Co-Optimization of Fuels \& Engines

\title{
Misfueling Mitigation
}

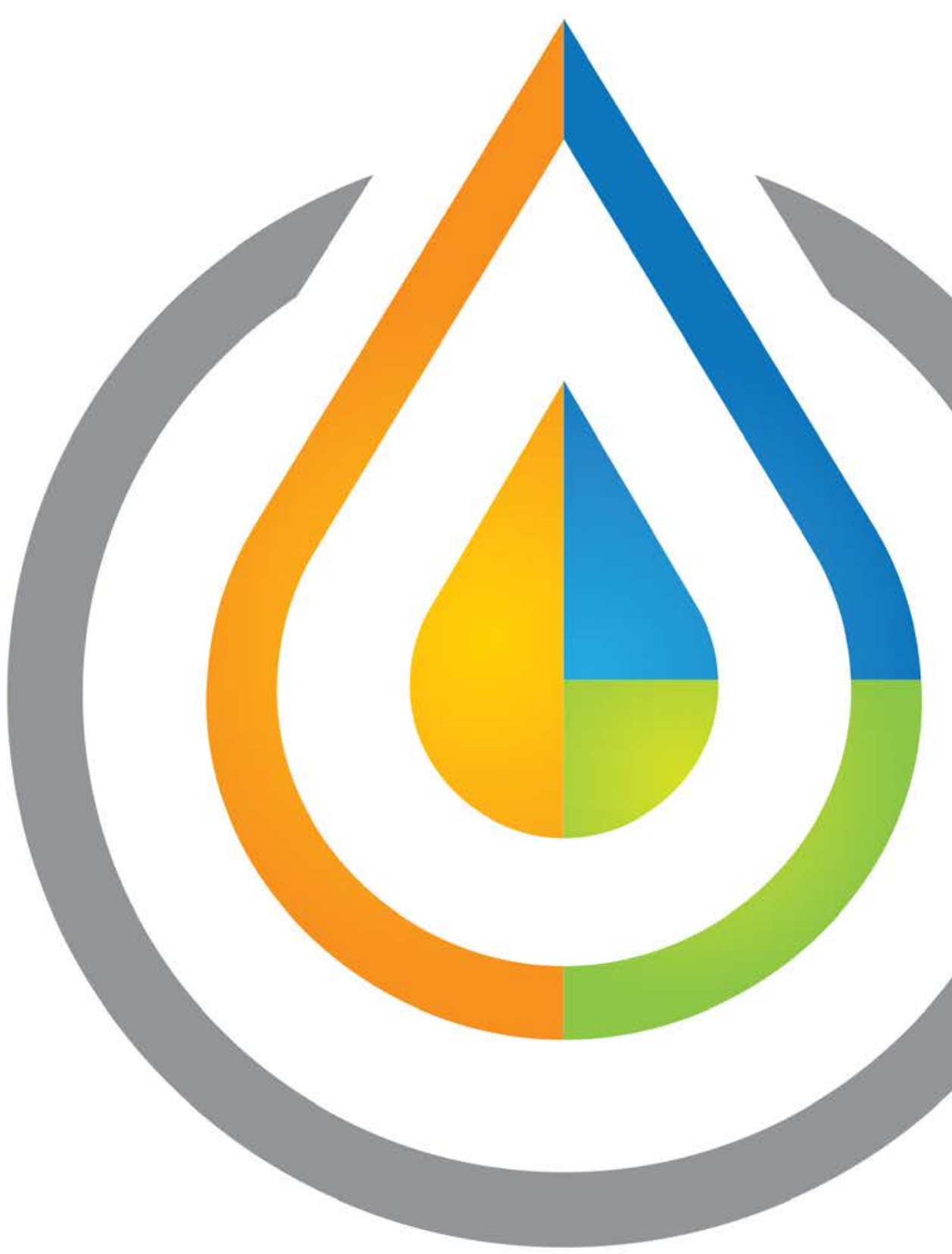




\section{About the Co-Optimization of Fuels \& Engines Project}

This is one of a series of reports produced as a result of the Co-Optimization of Fuels \& Engines (Co-Optima) project, a Department of Energy (DOE)-sponsored multi-agency project to accelerate the introduction of affordable, scalable, and sustainable biofuels and high-efficiency, low-emission vehicle engines. The simultaneous fuels and vehicles research and development are designed to maximize energy savings, reduce emissions, and enhance performance on the road.

The Co-Optima project brings together two DOE Office of Energy Efficiency \& Renewable Energy (EERE) research offices, nine national laboratories, and numerous industry and academic partners. These groups all seek to improve the types of fuels and engines found in most vehicles currently on the road. They also plan to develop revolutionary engine technologies for a longerterm, higher-impact series of solutions. This unique project will provide industry with the scientific foundation required to quickly move new biofuels and advanced engine systems to market while identifying and addressing barriers to commercialization.

In addition to the EERE Vehicle Technologies and Bioenergy Technologies Offices, the CoOptima project team included representatives from the National Renewable Energy Laboratory and Argonne, Idaho, Lawrence Berkeley, Lawrence Livermore, Los Alamos, Oak Ridge, Pacific Northwest, and Sandia National Laboratories. More details about the project, along with the full series of reports, are available at www.energy.gov/fuel-engine-co-optimization.

\section{Availability}

This report is available electronically at no cost from http://www.osti.gov/scitech.

\section{Citation}

Please cite as follows:

Sluder, Scott, Kristi Moriarty, Forrest Jehlik, and Brian H. West. Misfueling Mitigation. (Technical Report) Oak Ridge National Laboratory 2017. DOE/GO-102017-4896.

\section{Note}

This report was prepared as an account of work sponsored by an agency of the United States government. Neither the United States government nor any agency thereof, nor any of their employees, makes any warranty, express or implied, or assumes any legal liability or responsibility for the accuracy, completeness, or usefulness of any information, apparatus, product, or process disclosed, or represents that its use would not infringe privately owned rights. Reference herein to any specific commercial product, process, or service by trade name, trademark, manufacturer, or otherwise does not necessarily constitute or imply its endorsement, recommendation, or favoring by the United States government or any agency thereof. The views and opinions of authors expressed herein do not necessarily state or reflect those of the United States government or any agency thereof. 


\section{Report Contributors and Roles}

Lead Author

C. Scott Sluder, Oak Ridge National Laboratory (ORNL)

Co-Author(s)

Kristi Moriarty, National Renewable Energy Laboratory (NREL)

Forrest Jehlik, Argonne National Laboratory (ANL)

Brian H. West, ORNL 


\section{Acknowledgments}

The authors gratefully acknowledge the valuable viewpoints and technical information provided for this report by stakeholders in the private sector.

The following colleagues provided valuable feedback on this report in draft form:

Brian H. West, Deputy Director of the Fuels, Engines, and Emissions Research Center, ORNL

James M. Szybist, Senior Research Staff, ORNL

The following U.S. Department of Energy Office of Energy Efficiency and Renewable Energy (EERE) officials and managers played important roles in establishing the project concept, advancing implementation, and providing ongoing guidance:

Reuben Sarkar, Deputy Assistant Secretary for Transportation

Bioenergy Technologies Office

Jonathan Male, Director

Alicia Lindauer, Technology Manager

Borka Kostova, Technology Manager

Vehicle Technologies Office

Michael Berube, Director

Gurpreet Singh, Program Manager, Advanced Combustion Engines Program

Kevin Stork, Technology Manager, Fuel Technologies and Deployment

Leo Breton, Technology Development Manager

Mike Weismiller, Technology Development Manager

The national laboratory project management team consisted of:

John Farrell (Technical Monitor), NREL

John Holladay, Pacific Northwest National Laboratory (PNNL)

Robert Wagner, ORNL 


\section{Table of Contents}

List of Figures ...................................................................................................................... v

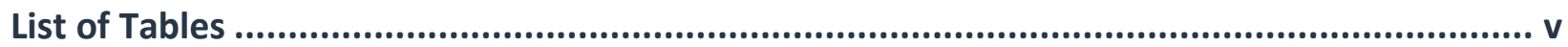

Abbreviations and Acronyms .............................................................................................

Executive Summary ..................................................................................................................

1 Introduction .................................................................................................................... 1

1.1 Purpose

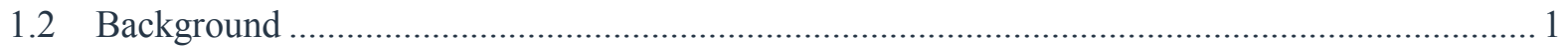

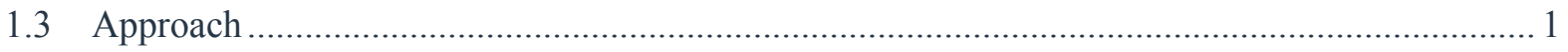

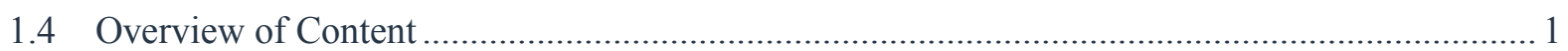

2 Experiences With Misfueling and Its Mitigation ............................................................... 2

2.1 Diesel - Gasoline Misfueling ............................................................................................2

2.2 Premium Grade - Regular Grade Choice ................................................................................ 3

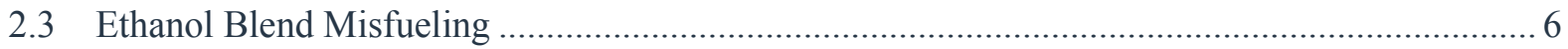

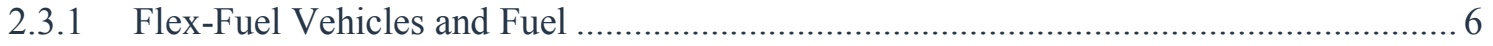

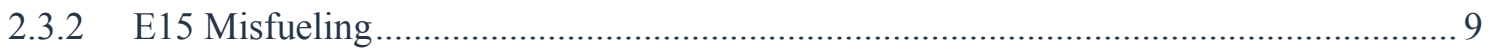

2.4 Regulatory Background for Premium-Required Vehicles ....................................................... 9

3 Potential Misfueling Mitigation Approaches to Support a New Fuel................................. 11

3.1 Gilson Environmental Report on E15 Misfueling Mitigation................................................ 11

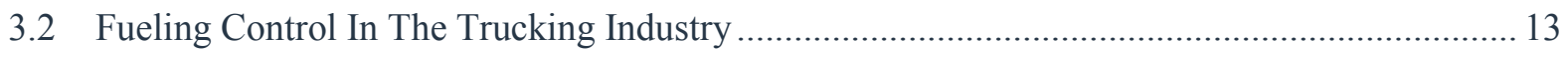

3.3 Connected Vehicle Technologies.............................................................................. 14

4 Stakeholder Viewpoints On Misfueling.............................................................................. 16

4.1 Fuel Retailers and Refueling Equipment Manufacturers ….................................................. 16

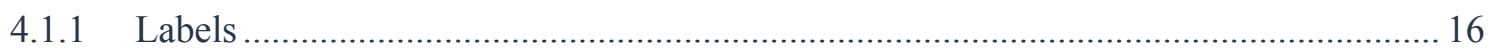

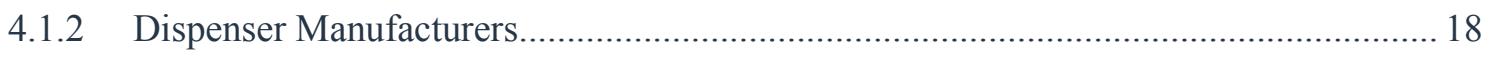

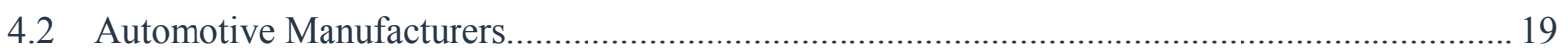

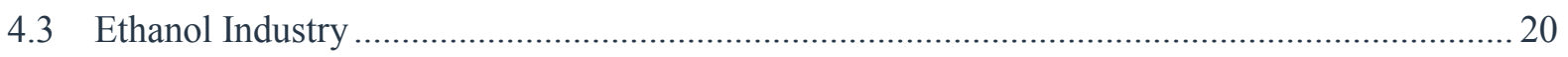

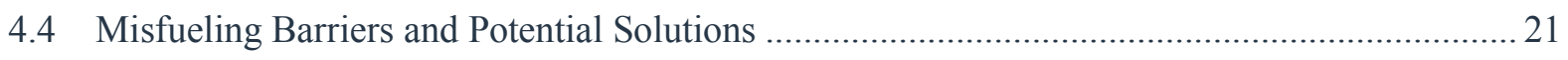

5 Codes and Standards Outreach .................................................................................... 22

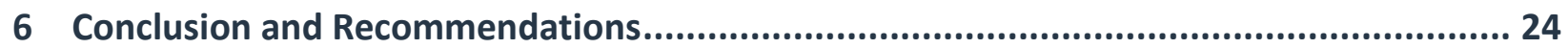

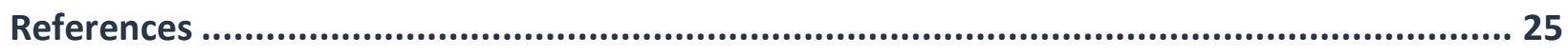




\section{List of Figures}

Figure 1. Anti-knock index (AKI) labels on a typical fuel dispenser. (Photo by Scott Sluder, Oak Ridge National Laboratory.)

Figure 2. Fuel Economy.Gov database records for manufacturer-specified fuel grade.............................. 4

Figure 3. A photograph of a typical fuel-grade guidance label inside a filler door. (Photo by Scott Sluder, Oak Ridge National Laboratory.)

Figure 4. Yellow fill port cap on a flex-fuel vehicle. (Photo by Scott Sluder, Oak Ridge National Laboratory.).....

Figure 5. FTC Flex-Fuel Dispenser Label Example for fuels between E11 and E50. (Image from Federal

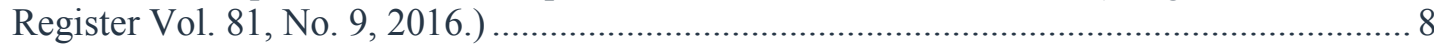

Figure 6. FTC E85 Flex-Fuel Dispenser Label. (Image from Federal Register Vol. 81, No. 9, 2016.) ....... 8

Figure 7. EPA E15 Dispenser Label. (Image from NREL's Handbook for Handling, Storage, and Dispensing E85 and Other Ethanol Blends, February 2016.) ........................................... 9

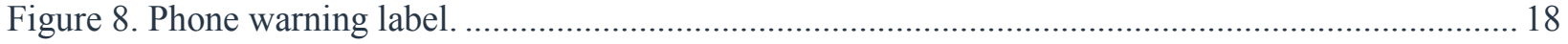

\section{List of Tables}

Table 1. Gilson Environmental report misfueling mitigation measure assessment matrix........................ 12

Table 2. Misfueling mitigation barriers and potential solutions. 


\section{Abbreviations and Acronyms}

AKI

API

BLE

CAFE

CI

DMV

DOE

E10

E15

E85

EERE

EMV

EPA

FFVs

FY

LLC

MON

NACS

RFA

RFID

RON

SI

ULSD anti-knock index (the average of RON and MON ratings)

American Petroleum Institute

Bluetooth Low Energy

Corporate Average Fuel Economy

compression ignition

Department of Motor Vehicles

U.S. Department of Energy

gasoline blend containing $10 \%$ ethanol by volume

gasoline blend containing $15 \%$ ethanol by volume

gasoline blend containing $85 \%$ ethanol by volume

DOE Office of Energy Efficiency \& Renewable Energy

Europay, MasterCard, Visa credit card standard

Environmental Protection Agency

flex-fuel vehicles

fiscal year

Limited Liability Corporation

motor octane number

National Association of Convenience Stores

Renewable Fuels Association

radio frequency identification

research octane number

spark ignition

ultra-low sulfur diesel 


\section{Executive Summary}

Misfueling is the act of filling a vehicle fuel tank with a fuel other than that which the vehicle manufacturer has specified. This report examines diesel/gasoline misfueling, leaded/unleaded gasoline misfueling, E85/E15/E10 misfueling, and consumer selection of regular grade fuel over premium grade fuel in an effort to evaluate misfueling technologies that may be needed to support the introduction of vehicle optimized for a new fuel in the marketplace.

During the 1970s, the implementation of catalytic emissions controls in the United States resulted in the deployment of unleaded gasoline. Unleaded gasoline deployment introduced the use of different nozzle geometries to the U.S. light-duty fleet as a misfueling mitigation strategy. Despite the use of nozzle geometry and pump labeling standards, misfueling persists as an issue in the retail fuel marketplace.

Misfueling can be either intentional or unintentional. Vehicle owners may be motivated to intentionally misfuel by a variety of factors. In some cases, they may be driven by an opportunity to purchase the lowest cost fuel blend available at the time of refueling. In other cases, the owners may choose a fuel with greater biofuel content, either to benefit the environment or to support local industry. Owners may also unintentionally misfuel if they are unaware of the correct fuel for their vehicle or equipment (such as legacy boats, motorcycles, and mowers) or if owners are confused by multiple options at the fuel pump.

Vehicles designed to use regular-grade gasoline can gain a marginal efficiency benefit by using premium-grade gasoline but the cost increase for premium-grade gasoline is usually greater than the benefit gained through better fuel economy. Though automotive manufacturers could design engines optimized for higher-octane fuel, they are hesitant to do so except in premium brands and performance models. This hesitancy is a result of concerns over possible customer satisfaction issues and increased warranty costs from misfueling.

According to automotive manufacturers, solving the misfueling issue may depend on two types of cross-compatibility: new fuel into legacy vehicles and legacy fuel into new vehicles. They determined that at least one of these types of misfueling would be likely (in the absence of an effective anti-misfueling measure) if the fuels differ in price or availability. With this issue in mind, misfueling mitigation should be considered throughout the industry rather than at specific manufacturers or fuel suppliers. Other industry stakeholders reiterated the need for a holistic strategy that is inclusive of legacy fuels, vehicles, and equipment. They agreed that vehicle-todispenser communication is probable, creating the need for a technical standard to facilitate broad adoption. Vehicle-to-dispenser communication also presents the opportunity to limit consumer choice to only those fuels for which the vehicle is designed, and as such is likely the most effective means of misfueling prevention.

A number of stakeholder organizations have provided input for the misfueling mitigation project. These groups agree that the effort should support and enable the acceleration of existing technology development programs. Such efforts include, for example, facilitating the development of technical standards for connected vehicle refueling approaches. Many stakeholders have also signaled their interest in participating in standard development activities. 


\section{Purpose}

This report explores current misfueling problems and future issues that may stem from the introduction of a new fuel and engine system into the marketplace, as well as potential pathways for mitigation.

Misfueling mitigation is critical for the successful introduction of a new fuel into the marketplace. Hence, it is a key issue that needs to be addressed as part of the Co-Optima project to introduce fuels and engines that improve fuel efficiency.

The objective of this study was to investigate possible mitigation strategies and to recommend actions for the project over the next several fiscal years.

This report is intended to be of interest to individuals in industry, government, and academia who are working to introduce a new fuel.

The authors consulted electronic resources and sought stakeholder input from the ethanol industry, automotive manufacturers, fueling equipment manufacturers, fuel retailers, and standards development bodies in the development of this report.

\section{Summary of Results}

The outcomes of this work include the development of this overview report on misfueling mitigation problems, the state-of-the-art resources in misfueling mitigation, the factors that will likely influence the problem in the future, and a recommended direction for the project within the Co-Optima program.

Regardless of the fuel introduced into the marketplace, a misfueling mitigation strategy will be needed to ensure that legacy vehicles not compatible with the new fuel are protected. The strategy will also ensure that new vehicles that require a new fuel are not misfueled with legacy fuel. Thus, developing a misfueling mitigation plan is a critical part of introducing new fuels and vehicles.

\section{Conclusions}

The key conclusion of this study is that a technical standard is needed to guide the industry-wide development of connected vehicle approaches to misfueling mitigation. The misfueling mitigation activity within the Co-Optima program should facilitate the formation of a committee within SAE International to develop this standard. 


\section{Introduction}

The Co-optimization of Fuels and Engines (or Co-Optima) initiative aims to identify the fuel properties and engine design characteristics needed to maximize the performance, environmental sustainability, and affordability of future vehicles. In this context, the introduction of a new fuel presents an increased risk of misfueling incidents. Misfueling occurs when a new vehicle designed for a new fuel is instead fueled with a legacy fuel, preventing its proper function, or when a new fuel is used in legacy vehicles that have not been demonstrated to be compatible with the new fuel. Misfueling mitigation strategies focus on preventing these issues. The Gilson Environmental Report, authored during the E1 $15^{1}$ introduction, catalogued a breadth of potential anti-misfueling measures and served as a starting point for the current study. Whereas electronic misfueling mitigation technologies have been identified as highly influential in the fuel marketplace, currently no technical standard can facilitate broad acceptance. Input from stakeholders in the automotive and fuel retailing areas has underscored the need for such a standard, as well as provided insight into several important aspects that should be addressed. The Co-Optima program is proceeding with efforts to assemble an inclusive committee to accelerate misfueling mitigation strategies in the marketplace.

\subsection{Purpose}

This report explores examples of misfueling problems and future issues that may stem from the introduction of a new fuel into the marketplace, as well as potential pathways for mitigation.

\subsection{Background}

The Co-Optima program involves the simultaneous identification of the low-carbon fuel properties and engine design characteristics needed to maximize the performance, environmental sustainability, and affordability of future vehicles. The Co-Optima project will provide industry stakeholders with the scientific underpinnings needed to quickly introduce new fuels and advanced engine systems to the marketplace. A key aspect of this effort is the identification of barriers to the deployment of co-optimized fuels and engines to the U.S. marketplace. This report focuses on one facet of deployment: the need for effective misfueling mitigation in the marketplace.

\subsection{Approach}

This study focused on review of the literature, online resources, and interviews with stakeholders to gather information relative to the state-of-the-art in misfueling mitigation and potential future directions for this research area.

\subsection{Overview of Content}

This report presents an overview of the problems and solutions associated with misfueling. Section 1 covers introductory material. Section 2 discusses experiences to date with misfueling and its mitigation. Section 3 examines potential future misfueling mitigation strategies. Section 4 contains input obtained from industry stakeholders. Section 5 addresses codes and standards outreach. Finally, section 6 contains the conclusions and recommendations from this study.

\footnotetext{
${ }^{1} \mathrm{E} 15$ is a gasoline blend that contains $15 \%$ ethanol by volume.
} 


\section{Experiences With Misfueling and Its Mitigation}

Misfueling is the act of filling a vehicle fuel tank with a fuel other than that which the vehicle manufacturer has specified for the vehicle to use. During the 1970s, the implementation of catalytic emissions controls in the United States resulted in the deployment of unleaded gasoline. Unleaded gasoline deployment introduced the use of different nozzle geometries to the U.S. light-duty fleet as a misfueling mitigation strategy. Since that time, the use of different nozzle geometries has become the standard misfueling mitigation strategy for diesel fuel, while the use of labeling standards has been adopted to mitigate misfueling among differing gasoline/ethanol blends, including E85. Despite the use of nozzle geometry and pump labeling standards, misfueling persists as an issue in the retail fuel marketplace. The following sections of this report outline misfueling issues as they exist today. It is difficult to arrive at reliable statistics on the rate of occurrence for each of these misfueling scenarios, but all are generally accepted by both the automotive manufacturers and retailers to be practical issues in the marketplace that influence decisions about optimizing vehicles for a fuel other than regular grade gasoline or diesel fuel.

\subsection{Diesel-Gasoline Misfueling}

Diesel engines and gasoline engines use different fuels because of their different ignition methods. Diesel engines are compression-ignition (CI) engines. With these engines, the fuel air charge ignites when compressive heating causes the temperature to exceed the autoignition temperature for the fuel being used (Heywood 1988). Fuel injection timing relative to the piston position is the primary means for controlling combustion phasing in these engines. Because fuels that autoignite easily are beneficial in CI engines, typical diesel fuels are made up of relatively high molecular weight straight-chain hydrocarbons, which tend to autoignite at lower temperatures than lower molecular weight branched-chain hydrocarbons. Cetane number is a fuel characteristic that rates diesel fuels according to their propensity to autoignite. A higher cetane number indicates fuels that more readily autoignited.

Gasoline engines are spark-ignition (SI) engines. In these engines, a spark initiates the combustion process (Heywood 1988). SI engines use fuels that are highly resistant to autoignition, so that the timing of the spark, rather than the charge temperature, controls combustion phasing relative to the piston position. Octane ratings describe the resistance of a fuel to autoignition, with higher octane corresponding to a greater degree of autoignition resistance. Research octane number $(\mathrm{RON})$ is most applicable to modern engines, but motor octane number (MON) was also useful in the past. Anti-knock index (AKI) is the average of RON and MON and is the octane rating that most consumers are familiar with, as this rating is posted on fuel dispensers, labeled $(\mathrm{R}+\mathrm{M}) / 2$. As shown in Figure 1, gasoline is typically sold in three grades: regular grade, mid-grade, and premium grade. Regular grade has the lowest AKI rating, which in most areas of the country is 87 AKI minimum. Premium grade has the highest AKI rating, typically either 91 or 93 AKI, depending on the station. Mid-grade is produced by blending regular grade and premium grade fuel by the fuel dispenser, producing an AKI rating that is typically 89 AKI minimum. 


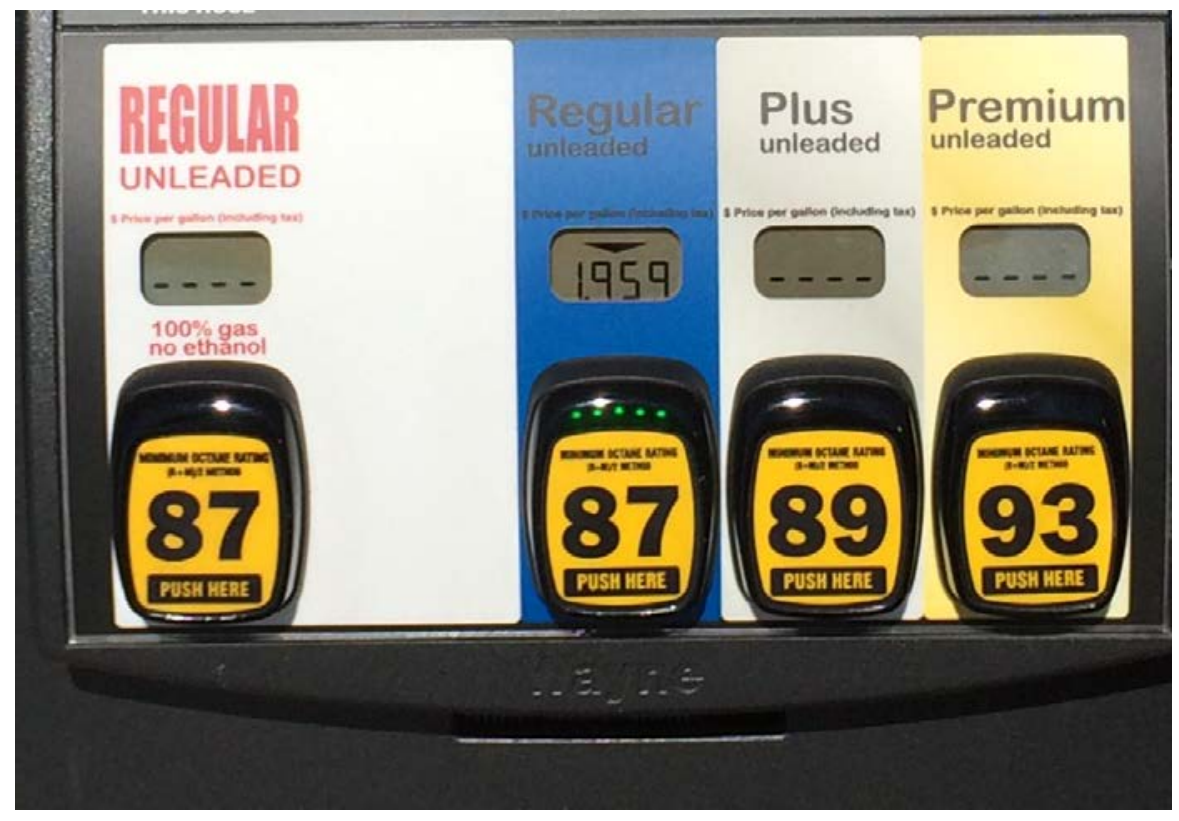

Figure 1. Anti-knock index (AKI) labels on a typical fuel dispenser. Photo by Scott Sluder, ORNL

Because CI and SI engines need different fuel autoignition conditions to function correctly, fuels designed for one are not generally compatible with the other. Therefore, it is important to avoid misfueling with these types of fuels.

For many years, misfueling mitigation for CI and SI vehicles has included the use of filler nozzles of differing diameter and labeling standards for both diesel fuel and gasoline. Because the nozzle for diesel (or CI) fuel is larger than that of gasoline (or SI) fuel, it is not possible to insert the diesel fuel filler into the fill port of an SI vehicle. However, it was possible to insert the SI fuel nozzle into the fill port of a CI vehicle for many years. Recent advances in fill port design for CI vehicles have addressed this issue, but not all manufacturers have adopted the feature. Original equipment manufacturers (OEMs) and station owners assume (and anecdotal reports support) that misfueling of diesel vehicles with gasoline does still occur.

Misfueling CI vehicles with SI fuel is an example of unintentional misfueling. Because filling a CI vehicle tank with SI fuel can result in immediate engine inoperability, there is a financial incentive for the consumer to use the correct fuel, regardless of the cost per gallon. In such cases, misfueling results from consumer confusion about which fuel their vehicle requires or which nozzle dispenses the fuel they need. The fuel recommended for use by the vehicle manufacturer is specified in the vehicle owner's manual and is displayed at the fill port. In addition to nozzle diameter, dispenser labeling is used to differentiate the fuels dispensed by the various nozzles at a refueling location. Often, gasoline and diesel are dispensed from the same dispenser but through different hoses. Unintentional misfueling occurs despite these mitigation efforts, although recent advances in fill port design could eventually resolve the problem if all manufacturers adopt this design approach.

\subsection{Premium Grade - Regular Grade Choice}

This example concerns consumers who drive vehicles for which premium-grade gasoline is either required or recommended by the manufacturer. The difference between the words 
"required" and "recommended" in reference to the use of premium fuel is significant. Premiumrequired vehicles are designed to operate using only premium fuel and may incur damage should a lesser grade fuel be used. However, premium-recommended vehicles are typically designed to operate on regular-grade gasoline, but will experience a performance increase if premium-grade fuel is used instead. For premium-recommended vehicles, the choice of a regular-grade fuel is not misfueling, but the consumer is choosing a fuel that reduces vehicle performance. A search of the www.fueleconomy.gov vehicle database shows that the number of vehicle models for which premium fuel is recommended has increased steadily over the past two decades, as shown in Figure 2 (Fuel Economy.Gov 2016). Before 2010, the records do not distinguish between premium-required and premium-recommended. Instead, the premium category is the sum of both subcategories. A record comprises a vehicle configuration; that is a vehicle model and powertrain configuration. For example, a 2016 Chevrolet Cruze was offered with both a 1.4 liter naturally-aspirated engine and a 1.4 liter turbocharged engine. Both of these configurations of the Cruze would have a record in the database. The database does not include sales volumes, and the graph does not reflect sales-weighted figures.

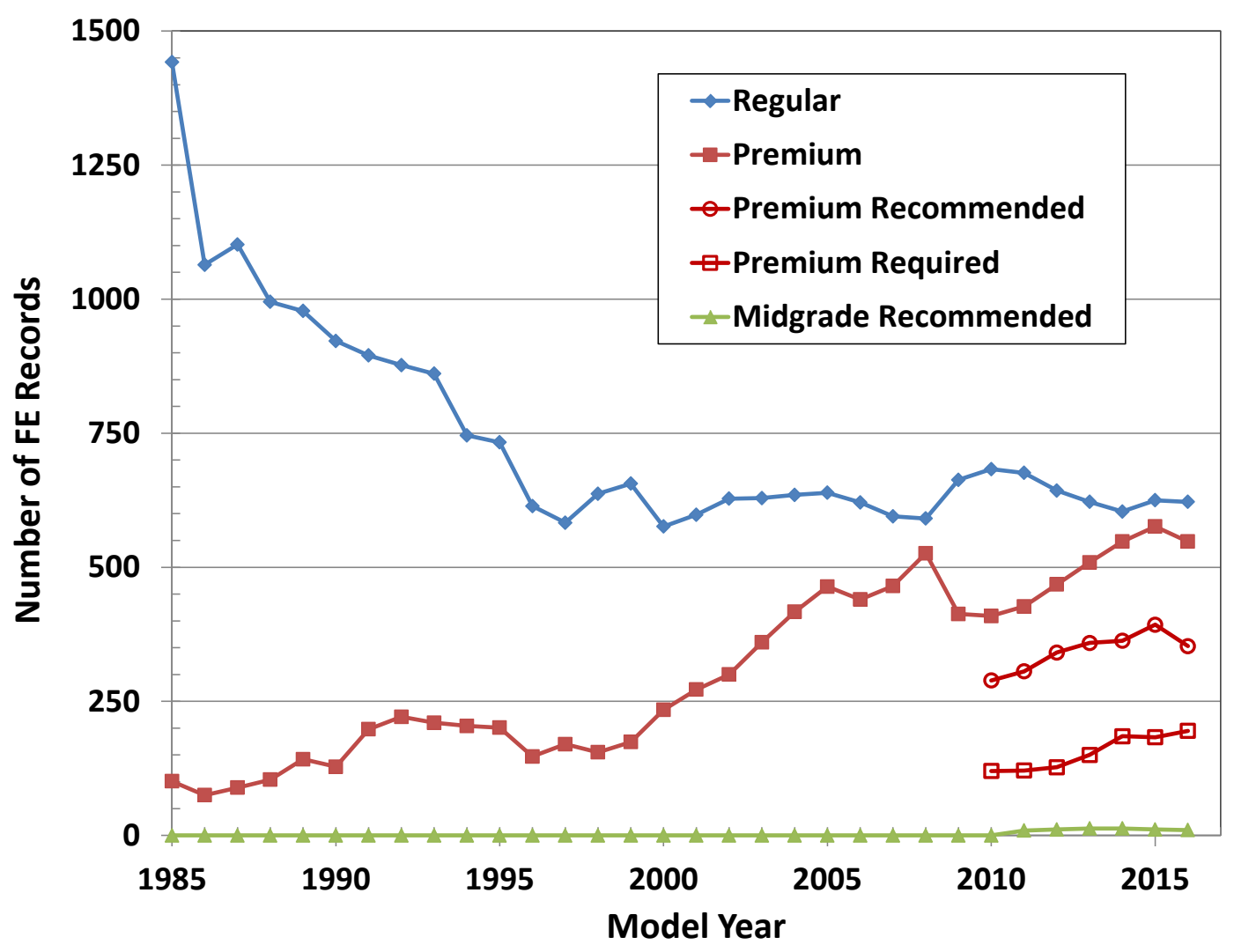

Figure 2. Fuel Economy.Gov database records for manufacturer-specified fuel grade 
Although the data show that premium-recommended and premium-required vehicle models are increasing in number, it is important to highlight the fact that these models tend to be to be premium car lines and sports cars, not higher-volume models such as sedans, sport-utility vehicles, and minivans. In 2016, the number of premium recommended models manufactured by Fiat-Chrysler Automobiles (FCA), Ford Motor Company, General Motors (GM), Toyota, Honda, Nissan, Mitsubishi, Volkswagen, Subaru, and Mazda in their non-premium car lines was 22. These models included differing configurations of the Chevrolet Corvette, Nissan 370Z, Scion FR-S, Subaru BRZ, Nissan GT-R, Chevrolet Camaro, Subaru WRX, and Chevrolet SS, all of which are performance models. The remainder of the 195 premium-required models in 2016 was produced in premium-car lines, including by Ferrari, Lamborghini, Porsche, Lexus, Infiniti, BMW, Mercedes-Benz, Cadillac, and others. Premium-recommended models are becoming more common among non-premium brands, but these cars are not designed to take full advantage of premium-grade fuel. Rather, they are designed to operate correctly using regular grade fuel and experience a performance boost when premium-grade fuel is used.

No published studies demonstrate the rate at which consumers with premium-recommended or premium-required vehicles choose regular-grade fuel. Most manufacturers view this behavior as a widespread issue, with consumers using a lower gasoline grade more often than not. Still, consumers who drive premium-required high-performance vehicles may be more motivated to use the correct fuel in an effort to avoid engine damage and to retain performance. Fuel cost may be a less important factor in fuel choice for these consumers.

Fuel selection guidance from the vehicle manufacturer is included in the vehicle owner's manual, and vehicles that need premium-grade fuel typically also have labels at the fill port and on the dashboard fuel level gauge (see Figure 3). Gasoline grades are marked on dispensers. No physical misfueling mitigation measures, such as use of different nozzle geometries, are used among different gasoline grades. Misfueling can be either unintentional (similar to gasoline/diesel misfueling) or deliberate. The former can result from consumer ignorance or confusion regarding the fuel needed for the vehicle. Intentional use of regular-grade fuel in lieu of premium-grade fuel is usually a result of consumers motivated to use the least expensive fuel available at the time of purchase. 


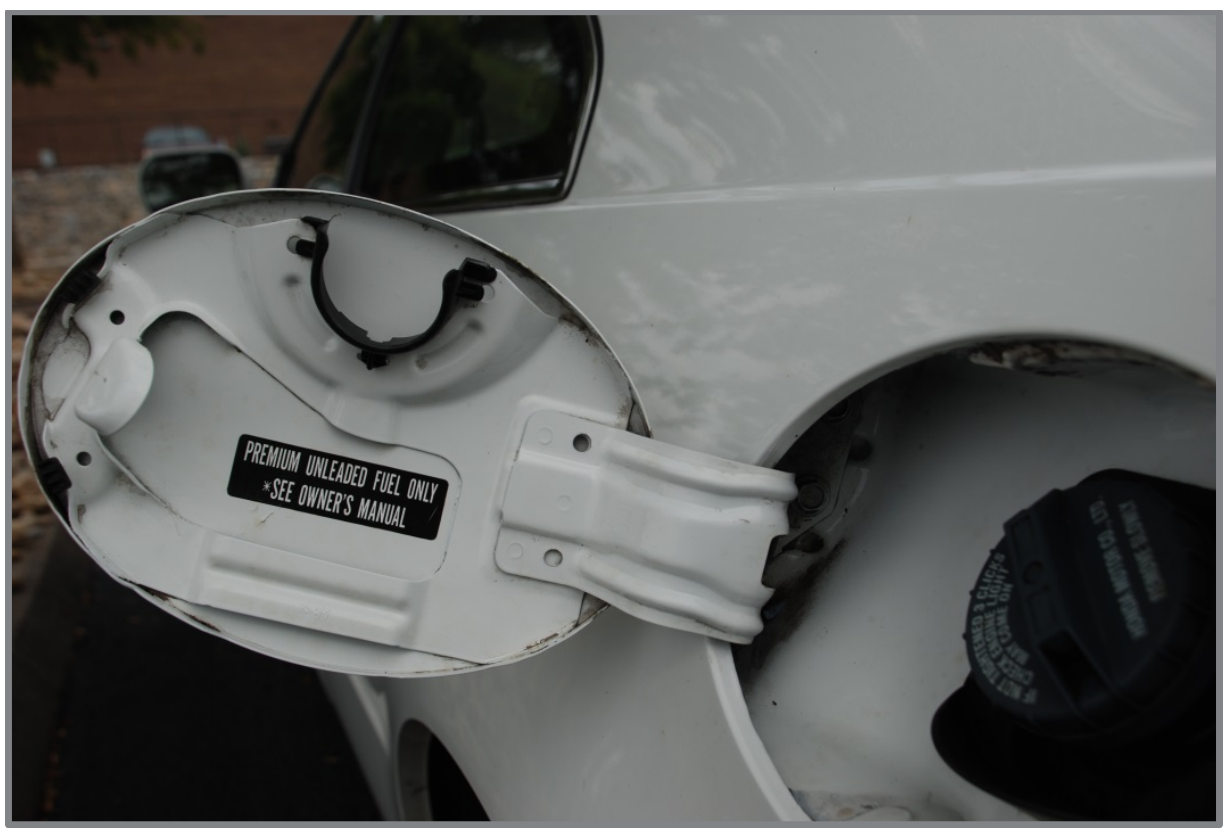

Figure 3. A typical fuel-grade guidance label inside a filler door. Photo by Scott Sluder, ORNL

\subsection{Ethanol Blend Misfueling}

\subsubsection{Flex-Fuel Vehicles and Fuel}

Flex-fuel vehicles (FFVs) use engines and fueling systems that can operate on any level of ethanol content from $0 \%$ to $83 \%$. The U.S. Environmental Protection Agency (EPA) requires that these vehicles comply with emissions regulations when using both E85 and gasoline fuels. Non-FFVs are designed to operate correctly with fuels that contain lower blend levels of ethanol, typically a maximum of either $10 \%$ ethanol by volume (E10) or $15 \%$ ethanol by volume (E15). 


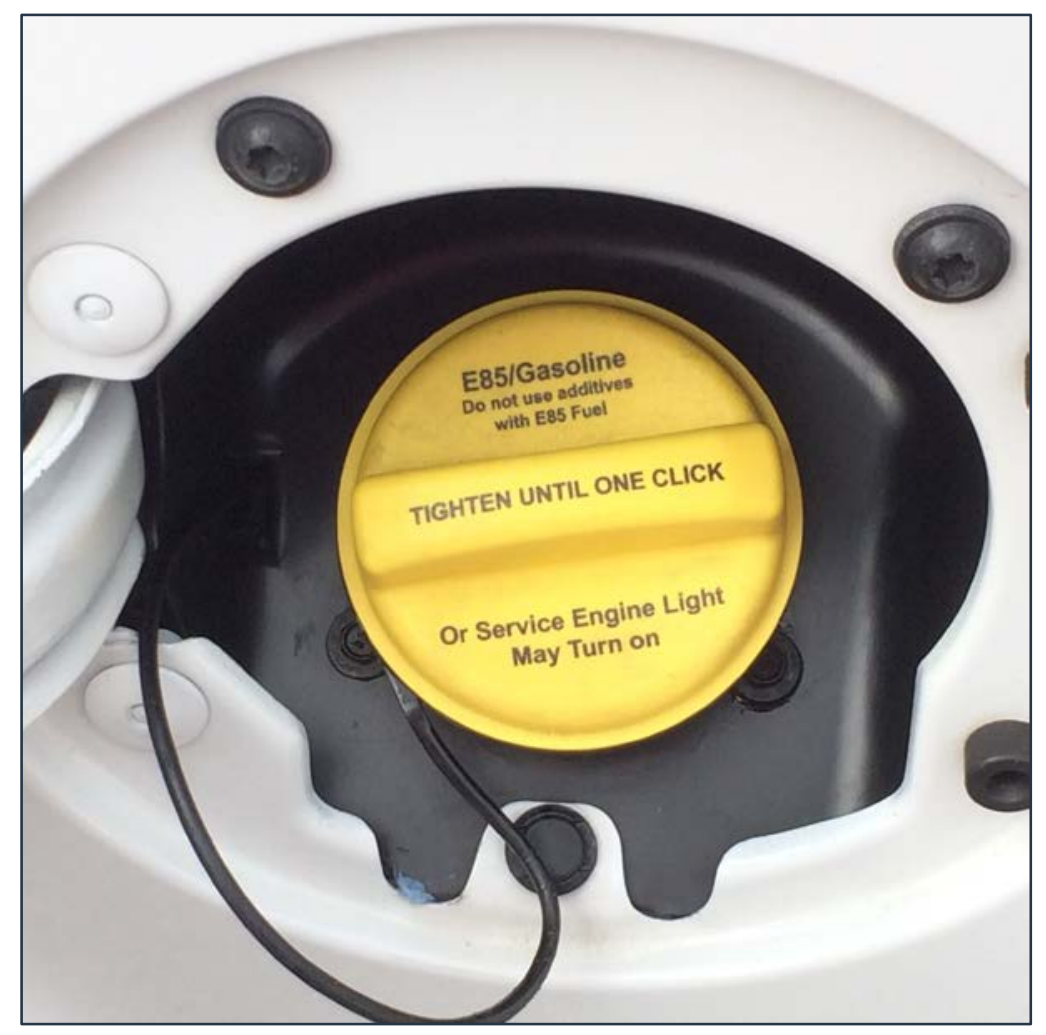

Figure 4. Yellow fill port cap on a flex-fuel vehicle. Photo by Scott Sluder, ORNL

Nearly all retail stations offer E10 and nearly 3,000 offer E85 (also known as flex-fuel)—a term that refers to high-level ethanol-gasoline blends containing 51\%-83\% ethanol, depending on geography and season. Some stations also offer mid-level blends such as E20 or E30 to give FFV owners a choice of fuels. Most, but not all, stations offer E10+ fuels through blender pumps which draw fuel from two tanks to offer multiple fuels. The blender pump pulls from a regular gasoline (E0 or E10) tank and an E85 tank to offer mid-level ethanol blends.

The Federal Trade Commission (FTC) develops dispenser labels to educate consumers and reduce incidents of misfueling. They recently updated their E85/ethanol flex-fuel labeling requirements. For ethanol flex-fuel blends above E10 and up to E50, the retailer must label within 10\% of ethanol content (Figure 5) (Federal Register 2016). Figure 6 shows the label for ethanol flex-fuel, typically marketed as E85. 


\section{0\% ETHANOL}

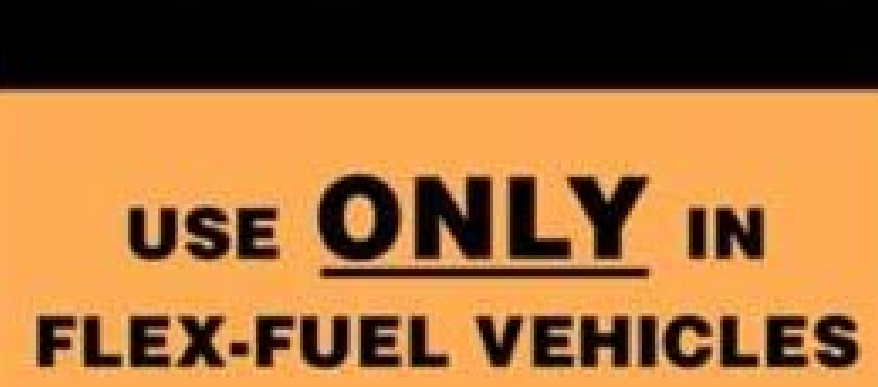

MAY HARM OTHER ENGINES

Figure 5. FTC flex-fuel dispenser label example for fuels between E11 and E50. Image from Federal Register Vol. 81, No. 9, 2016

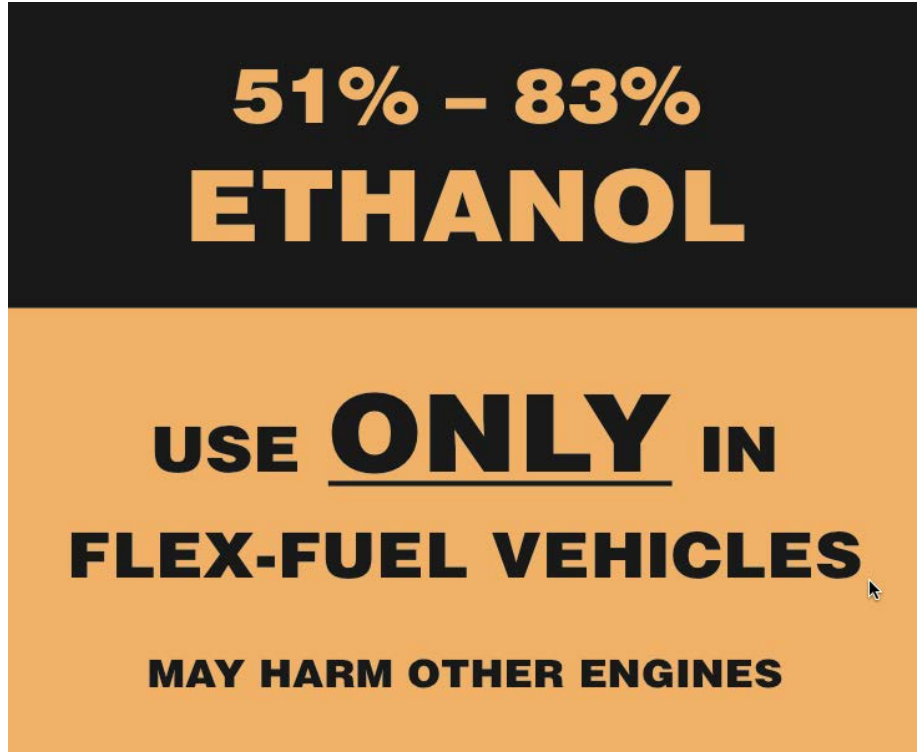

Figure 6. FTC E85 flex-fuel dispenser label. Image from Federal Register Vol. 81, No. 9, 2016

To prevent misfueling, FFVs often use a yellow fill port cap and external badging to identify the vehicle as an FFV and make owners aware they can use E85 in their vehicle (see Figure 4) (Fuel Economy.Gov 2016). It is possible that some vehicle owners may intentionally use higher ethanol blends such as E30 in their non-FFVs though there are not data or publications on this type of behavior. A potential reason a consumer may intentionally misfuel is due to lower prices. This behavior violates both the vehicle warranty and environmental regulations, as these vehicles are not designed to use fuels containing more than 10\%-15\% ethanol. The elevated ethanol content can cause premature failure of the fuel system or engine and may also result in excessive 
emissions. Because these issues do not usually arise immediately, some owners may not associate increased maintenance costs or premature component failures with their choice to misfuel. Owners may be motivated to misfuel by a variety of factors.

\subsubsection{E15 Misfueling}

Gasoline blends were limited to contain at most 10\% ethanol (E10), but EPA decisions in 2010 and 2011 increased the allowable level of ethanol to 15\% (E15) for 2001 and newer model year vehicles (Federal Register 2010; Federal Register 2011). The division of the fleet created with the introduction of E15 is in some ways comparable to the division of the fleet into FFVs and non-FFVs. Eighty percent of 2017 model year vehicles are designed to operate on ethanol blends from $0 \%-15 \%$, though some manufacturers continue to specify ethanol blends from $0 \%-10 \%$ for their new models (RFA 2016). The bifurcated market where some, but not all, existing vehicles were approved for E15 use led EPA to require a misfueling mitigation plan that was developed for the ethanol industry. This plan focused on the use of dispenser labeling, as shown in Figure 7 (E15 Retailer Handbook 2012). It was not practical to consider a different nozzle geometry since the filler neck is the same for SI vehicles regardless they were manufactured before or after 2001. There is little to no information available on E15 misfueling. Given the limited market penetration of E15 and the shrinking number of registered vehicles that are prohibited from its use, this problem should be less significant in the future.

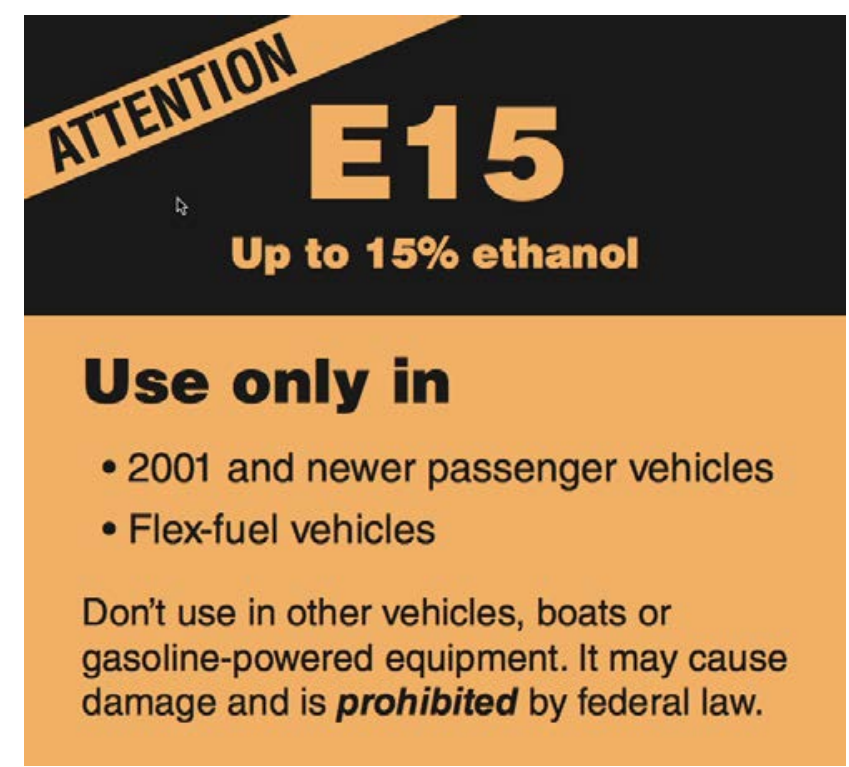

Figure 7. EPA E15 dispenser label. Image from NREL's Handbook for Handling, Storage, and Dispensing E85 and Other Ethanol Blends, February 2016

\subsection{Regulatory Background for Premium-Required Vehicles}

Since the mid-1990s, virtually all emissions and fuel economy certification tests were conducted using a premium-grade ethanol-free certification fuel. The emergence of knock sensors led EPA to require manufacturers to prove that fuel economy results for tests using premium-grade fuel would not be degraded by more than $3 \%$ had a regular-grade fuel been used instead (EPA Mailout VPCD-97-01, 1997). During this period, premium-required and premium-recommended vehicles were treated in the same way as vehicles that were designed to use regular-grade gasoline from a certification perspective. 
With the introduction of the Tier 3 emissions requirements, EPA altered the emissions certification fuel selection to be more reflective of the fuel marketplace. With this change, all vehicles will use a regular-grade certification fuel except vehicles that are premium-required, which will use a premium-grade certification fuel during emissions testing. To qualify for this fuel, vehicles must require premium-grade gasoline as a condition for the validity of the vehicle warranty (Federal Register 2014). In contrast, vehicles for which premium fuel use is recommended as a performance-enhancing measure will not qualify to use premium-grade certification fuel.

After 2020, vehicle manufacturers will be able to gain a Corporate Average Fuel Economy (CAFE) benefit through increasing fuel octane rating, which can be done by requiring premium fuel use. However, because of the prolific nature of misfueling, the manufacturers currently "protect" their engine systems against possible damage by designing the engine to use regulargrade fuel. They also reduce engine performance to avoid damage when sub-octane (85 AKI) gasoline is used. Sub-octane gasoline is available in states in the Rocky Mountain region, and consumers in those states use it regularly despite the fact that vehicle owner's manuals specify fuel with at least an 87 AKI rating. Vehicles designed to use regular-grade fuel can gain a marginal efficiency benefit by using higher-grade fuel but the cost increase for higher-grade fuels is usually greater than the benefit gained through better fuel economy. Currently, consumers are not motivated to use the high-octane fuel that would be required by the vehicle warranty (or misfueling prevention technology). Though automotive manufacturers could design engines optimized for higher-octane fuel, they are hesitant to do so because of possible customer satisfaction issues and increased warranty costs from misfueling. 


\section{Potential Misfueling Mitigation Approaches to Support a New Fuel}

An objective for this project was to identify potential misfueling mitigation approaches that could be developed as a part of deployment to support a new fuel blend. Some approaches, such as the use of different nozzle geometries for different fuel blends, are relatively common, but others are rare or still under development. A key aspect of evaluating misfueling mitigation approaches or technologies is whether the new fuel is universally "backwards-compatible." In most cases, it is difficult to imagine that a new fuel capable of significantly improving engine efficiency can be used in all earlier models. One exception to this statement is a high-octane E10. However, a recent study has shown that producing such a fuel would likely increase refinery costs and $\mathrm{CO}_{2}$ emissions (Hirshfeld 2014), making such a fuel less attractive. Regardless, vehicle manufacturers and EPA will likely require assurance that new vehicles designed to use a highoctane fuel would only use the correct fuel. Thus, a new fuel is likely to result in a marketplace division similar to that experienced with flex-fuel vehicles or E15. Furthermore, because a new vehicle that is designed to use this hypothetical new fuel would need to avoid the use of fuels that lower its efficiency to retain an attractive CAFE benefit, existing fuels will not be universally forward compatible either. Even if complete migration of new vehicles to the new fuel is anticipated, the lengthy time period required for fleet turnover mandates availability of both fuels (and thus misfueling mitigation strategies as well) during the transition.

\subsection{Gilson Environmental Report on E15 Misfueling Mitigation}

During the introduction of E15 to the marketplace, the American Petroleum Institute (API) commissioned Gilson Environmental LLC to investigate and report on potential misfueling mitigation measures that could be employed for use with mid- to high-level ethanol blends (Gilson 2010). The objective of this report was to identify measures to reduce the misfueling of vehicles with mid- to high-ethanol blend fuels. The report anticipated the possibility that EPA would approve the use of E15 in some vehicles while disallowing it in other vehicles. In total, 18 measures were identified and assessed by Gilson Environmental in terms of their anticipated effectiveness, acceptance by consumers and retailers, feasibility, and cost. The ratings are based on the judgement of the study authors, and not on any experimental studies. These measures are summarized in Table 1. Because E15 was being considered in the context of being backwardcompatible, the report anticipated the need for retrofits to existing vehicles as well as changes to new vehicle designs before manufacturing.

Of the 18 measures identified, Gilson Environmental concluded that 5 were not likely to effectively prevent misfueling. These measures included dispenser labeling, separate islands for gasoline and high-ethanol fuels, vehicle identification cards to aid in fuel sales of high-ethanol blends, restricted credit/debit cards, and a dispenser-based vehicle ID requiring the owner to indicate whether they have an FFV or E15-legal non-FFV. 
Table 1. Gilson Environmental Report: Misfueling Mitigation Measure Assessment Matrix

\begin{tabular}{|c|c|c|c|c|c|}
\hline Measure & Effectiveness & $\begin{array}{l}\text { Customer } \\
\text { Acceptance }\end{array}$ & Feasibility & Cost & $\begin{array}{l}\text { Timeframe for } \\
\text { Implementation }\end{array}$ \\
\hline Dispenser Labeling & Low & High & High & Low & Short \\
\hline $\begin{array}{l}\text { Separate Islands for } \\
\text { Gasoline and High Ethanol } \\
\text { Fuels }\end{array}$ & Low & Low & Low & High & Short \\
\hline Refueling Attendant & High & $\begin{array}{l}\text { Medium to } \\
\text { High }\end{array}$ & Low & High & Short \\
\hline $\begin{array}{l}\text { Full Service Attendant with } \\
\text { Dispenser Lockout }\end{array}$ & High & $\begin{array}{l}\text { Medium to } \\
\text { High }\end{array}$ & Low & High & Short \\
\hline $\begin{array}{l}\text { Cashier Fueling Permission } \\
\text { with Dispenser Lockout }\end{array}$ & High & Low & Low & Low & Short \\
\hline Vehicle Identification Card & Low & $\begin{array}{l}\text { Low to } \\
\text { Medium }\end{array}$ & $\begin{array}{l}\text { Low to } \\
\text { Medium }\end{array}$ & Medium & Long \\
\hline $\begin{array}{l}\text { Restricted Credit/Debit } \\
\text { Cards }\end{array}$ & Low & Low & Low & Medium & Long \\
\hline $\begin{array}{l}\text { Large Diameter Dispensing } \\
\text { Nozzle }\end{array}$ & High & Low & Low & High & Long \\
\hline RFID Option 1 & High & Medium & Low & High & Medium \\
\hline RFID Option 2 & High & Low & Low & High & Long \\
\hline Vehicle ID Option 1 & Medium & Low & Low & High & Long \\
\hline Vehicle ID Option 2 & Low & Low & Low & Medium & Long \\
\hline Talking Dispenser & Medium & Low & Low & High & Long \\
\hline DMV Mailing & Medium & Medium & Medium & Low & Medium \\
\hline Nozzle Hand Warmers & Medium & High & High & Low & Short \\
\hline $\begin{array}{l}\text { FFV Identification using a } \\
\text { Website }\end{array}$ & Medium & Medium & High & Low & Short \\
\hline $\begin{array}{l}\text { FFV Identification Using a } \\
\text { Smart Phone Application }\end{array}$ & Medium & Medium & High & Low & Short \\
\hline Public Education Program & Medium & Medium & High & $\begin{array}{l}\text { Low to } \\
\text { Medium }\end{array}$ & Short \\
\hline
\end{tabular}

The Gilson Environmental report concluded that 7 of the 18 measures had a medium effectiveness for misfueling prevention, meaning that they were judged by the report authors to have the potential to reduce misfueling but not stop it. These measures included a different vehicle identification option, a DMV mailing, different nozzle hand warmers, FFV identification using a website, a smart phone application, and a public education program. 
Six of the 18 measures were assessed to be highly effective by the Gilson Environmental report authors. Rather than focusing on the vehicle owner, three of these measures focused on a different person's involvement during a transaction, either as a trained fueling attendant or as a cashier. In these cases, the attendant or cashier provided an approval to fill with the mid-level ethanol blend after identifying the vehicle as approved to use such a fuel. Gilson Environmental deemed these measures to have either a high cost or a low feasibility because retail station owners would not support these measures.

The Gilson Environmental report highlighted the use of a large diameter dispensing nozzle as highly effective despite low feasibility and high cost, both of which were stated to result largely from the need for and difficulty in enforcing broad-scale retrofits to existing vehicles. Experience with this tactic as a misfueling prevention measure for diesel fuel demonstrates that it may not be enough on its own. However, modern filler neck designs may alleviate this concern.

Nevertheless, the addition of a third-nozzle geometry into the marketplace would add complexity and the potential for consumer dissatisfaction. This measure could be workable, though perhaps not optimal. Overall, the measure would not likely benefit from further development under the Co-Optima program.

The last two measures that Gilson Environmental assessed as being highly effective were both radio frequency identification (RFID) tag-based measures. One measure focused on the use of a tag in the form of a key-fob carried by consumers who have an FFV or E15-approved vehicle. This measure could effectively control the sale of a new fuel to an appropriate consumer, but not necessarily to the appropriate vehicle. It would not prevent consumers from using legacy fuel for vehicles designed for a new fuel. The second RFID measure involved the use of RFID tags built into new cars or retrofitted into older cars, likely in the area around the filler neck. This measure could be highly effective at preventing misfueling, provided that the attachment of the RFID tags to the vehicle is secure against tampering. The Gilson Environmental report assessed this measure to be costly, based in large part on the increased need for retrofits.

Considering the Gilson Environmental report's ratings in the context of the Co-Optimization program suggests some approaches that merit further study within the program and many that do not. Measures that Gilson Environmental rated as low- or medium-effectiveness were deemed insufficient by the Co-Optimization program misfueling mitigation team and not considered for further development within the program. This decision was based on the need for highly effective misfueling mitigation technologies that prevent misfueling both of new, co-optimized vehicles and legacy vehicles. Technologies such as the RFID options identified in the Gilson Environmental report that were deemed by Gilson Environmental to be highly costly may be worth revisiting within the co-optimization program if the new fuel is not intended to be backwards-compatible, as this case would avoid the need for extensive vehicle retrofits. Furthermore, the cost of RFID (and other digital) technology has dropped in the last several years, perhaps making this measure viable for consideration.

\subsection{Fueling Control In The Trucking Industry}

The trucking industry has been more aggressive in adopting fueling control methods that are driven by electronic measures. In this industry, fueling issues are most frequently associated with assigning the correct fuel costs to the correct trucking company at the refueling station. That is, fueling control in this context is primarily associated with preventing fuel theft, rather than 
preventing fueling of a truck with the incorrect fuel formulation. A number of systems have been deployed, all with similar goals but often with different sensing technologies or combinations of technologies in an effort to make the system stronger. For example, the Gasboy FuelPoint PLUS system uses wireless vehicle identification to ensure that the fueling nozzle is inserted into an authorized vehicle before fueling, and can accept feedback from a vehicle module to gather odometer readings and other information. This system eliminates the need for keys or cards that can be lost or misused (Gasboy 2009). Gasboy is owned by Gilbarco Veeder-Root, a refueling equipment manufacturer. Similarly, the TCH Z-Con system and the SmartQ RFID-based system identify authorized vehicles before allowing refueling. Several other systems are at truck stops nationwide.

While the deployment of many electronic systems to control fueling in the trucking industry points to the feasibility and effectiveness of adopting similar systems in the light-duty fuel retailing sector that the co-optimization program is targeting, it also highlights a potential issue. Deployment of many systems in the light-duty sector would mean that a consumer might need multiple technologies in their vehicle to make use of a breadth of different fueling stations, each of which might have a different misfueling technology. Such an outcome would work against broad adoption of misfueling mitigation technologies and retard the market penetration of a new vehicle and fuel combination. Development of a technical standard to underpin misfueling mitigation technologies could prevent this issue. A Transport Topics article highlighted the issue of proliferation of these systems in the trucking industry without a technical standard to achieve broader acceptance, including a quote from Dan Alsaker of Broadway Truckstops that supports the need for a technical standard. (Johnson 2011).

\subsection{Connected Vehicle Technologies}

A logical extension of the RFID-based measures identified in the Gilson Environmental report and recent technology developments in the trucking industry is the use of electronic systems to allow communications between the vehicle and the fuel dispenser. Such approaches are a subset of the connected vehicle technologies. Toyota and SAP have begun to explore the use of a connected refueling technique to increase convenience for customers. This implementation of connected refueling uses the infotainment system within the vehicle to communicate with the dispenser, allowing completion of a refueling transaction (SAP 2016). A similar approach being investigated by SAP and Volkswagen makes use of consumers' smartphones in place of the vehicle infotainment system to accomplish the same objective (SAP 2016). These approaches can include identification of the correct fuel for the vehicle in a transparent way.

Using connected vehicle technology has the potential to be the most effective means of misfueling mitigation, as it allows the vehicle and the dispenser to directly communicate the necessary information to complete a fuel transaction. As this information can be coded into the vehicle during production, there is much less potential for subsequent tampering by consumers. Because most new vehicles already contain the hardware for substantial wireless communication, it is likely that costs to add a connected refueling functionality to new vehicles would be relatively low. However, adding functionality to retail refueling equipment would be necessary.

As with the trucking environment, there is not currently a technical standard in place to ensure that developing connected refueling measures are consistent enough to support widespread adoption. Other connected vehicle standards are under development to support vehicle-to-vehicle 
and vehicle-to-infrastructure communication. Addressing vehicle-to-dispenser communication uses the explosive growth of connected vehicle technologies in a new way to help improve fuel economy by eliminating the misfueling problem. 


\section{Stakeholder Viewpoints On Misfueling}

Staff at Oak Ridge National Laboratory (ORNL), National Renewable Energy Laboratory (NREL), and Argonne National Laboratory (ANL) assembled a presentation outlining the measures presented in the Gilson Environmental report, current directions in the trucking industry, and Co-Optima objectives for establishing communications with stakeholders in the misfueling mitigation technical area. Multiple meetings were conducted with stakeholders, both individually and in small groups to facilitate open communication. The following sections of the report outline the input received from stakeholders in the retail, automotive manufacturing, refueling equipment manufacturing, and biofuel industries.

\subsection{Fuel Retailers and Refueling Equipment Manufacturers}

\subsubsection{Labels}

The most common misfueling event involves premium-required vehicles refueling with regular gasoline, but this issue is not a liability or cost concern for retail station owners. The negative effects that result from this type of misfueling may take time to make a noticeable impact. Thus, most customers will probably not notify a retail station about any misfueling.

Some station owners will cover costs to drain the fuel tanks for customers who mistakenly misfuel diesel into a SI engine or gasoline into a CI engine. Station owners saw the potential for misfueling liability and fines under the Clean Air Act with E15 since this relies on consumers knowing what year vehicle they are driving. ${ }^{2}$ General consensus is that nearly all consumers know if they are driving a vehicle that requires gasoline or diesel but fewer consumers can recall the model year of their vehicle.

Retailers rely on dispenser labels to reduce the risk of misfueling as required by regulations. Typically, FTC oversees dispenser labels. However, EPA developed labels before the introduction of ultra-low sulfur diesel (ULSD) and E15 due to the fuels moving into the market more quickly than FTC's timeline to introduce new labels. In the case of ULSD, engines with model year 2007 and newer required the fuel because the higher sulfur diesel would cause malfunctions of the emissions control systems for these engines. For 3 years, both low sulfur diesel and ULSD were available in the market. However, a 2006 EPA survey found that $90 \%$ of stations were selling ULSD but only $24 \%$ of dispensers were labeled as selling ULSD (EPA 2007). The EPA issued a letter in January 2007 stating that the dispensers had to be labeled, as the retailers were out of compliance with regulation and subject to penalties under the Clean Air Act. Similarly, EPA required a label for E15 because of the divided market where only light duty vehicles model year 2001 and newer could use the fuel (see section 2.3.2 and Figure 7).

Generally, to reduce consumer confusion, nozzles are certain colors for certain fuels. In the United States green nozzles usually indicate diesel and yellow usually indicate E85. However, this color coding could not be required because $50 \%$ of stations are branded by an oil or refinery company that may stipulate certain nozzle colors in their contract for marketing purposes.

\footnotetext{
${ }^{2}$ Misfueling is considered a violation of the Clean Air Act and stations can be fined for intentional and unintentional misfueling. More information is available from the EPA: https://www.epa.gov/enforcement/clean-air-act-fuelssettlement-information.
} 


\subsubsection{Retail Station Payment Systems}

A potential opportunity to reduce incidence of misfueling is to integrate prevention into mobile payment systems. Fuel retailers are unique in that they must accept payment both outside for fuel and inside for fuel and convenience store purchases. When paying for refueling, $78 \%$ of consumers use a credit or debit card (NACS 2015). Changes in payment systems to decrease fraud have compelled retailers to upgrade their payment and dispensing systems. To accept debit cards, retailers had to upgrade payment systems and retrofit electronics in their dispensers to accommodate pin encryption by July 2010. Currently, retailers are upgrading dispensers through either a retrofit or replacement to accept EMV (Europay, MasterCard, Visa) technology. This technology requires the credit card to be inserted, and the device reads a chip rather than using the magnetic strip. Although not a federal requirement, upgrading these systems is practical because credit card companies intend to shift fraud liability to retailers by October 2017 if they have not upgraded to accept chip credit cards. Some have commented that the upgrade to EMV technology is costly to the retail sector and will likely be replaced in upcoming years by mobile payment systems. The upgrading of existing dispensers to accommodate various payment requirements creates an opportunity to also accommodate technology for misfueling prevention.

While misfueling is not currently a significant concern for retailers, new technologies for mobile payments could potentially add misfueling prevention technology. The motivation for retail station owners to expend additional funds for mobile payment systems is the opportunity to reduce transaction costs. The National Payment Card Association charges 15 cents per transaction for mobile pay regardless of the volume of fuel purchased, whereas average costs at the pump or in-store for credit cards and regulated debit cards are 6 cents/gallon and 2.4 cents/gallon, respectively (NACS 2015). High payment transaction fees are a concern for retail stations. In 2013, convenience stores reported $\$ 7.1$ billion in profit and $\$ 11.2$ billion in credit card fees (NACS 2015). Although fuel accounts for $70 \%$ of sales at a station, it only accounts for $30 \%$ of profits. Thus, retailers with mobile payments could reduce costs and offer incentives via a mobile app to get consumers into the store boosting profits for both fuel and in-store sales. There is the potential for existing and future mobile payment systems to include technology that limits which fuels a consumer can purchase to those that are approved for their vehicle.

Examples of retail fueling mobile payment systems include the following.

- Chevron began mobile payments at 20 stations in Northern California in fall 2015. Payments are restricted to Visa and made through Visa's Token Service in which a mobile phone touches an area of the dispenser to make payment (Samuely 2015).

- Cumberland Farms SmartPay mobile app uses ZipLine NPCA technology for payment, and the consumer enters the store and pump number into the app. Currently, the app provides a 10 cent/gallon discount for mobile payment and a free drink after 40 gallons are purchased. The app can also be used for in-store purchases (Smartpay 2016).

- Mapco has an app system and has collaborated with PayPal for mobile payments (Hamstra 2014).

- ExxonMobil has a different approach with Speedpass, a key tag payment system that links to a consumer's credit or debit card for quick payment (Speedpass 2016). 
Challenges for retail station mobile payment and potential misfueling mitigation technology include the following.

- There is no standardization of mobile payment apps.

- Potential solution: engage CONEXXUS, a technology standards organization started by the National Association of Convenience Store Owners.

- Each retailer has its own app. It is unclear if consumers would be willing to have multiple apps.

- Potential solution: a universal app like PayPal. It would need to incorporate the various retailer rewards programs.

- Retailers are sensitive to any activity that delays or causes refueling time to increase.

- Potential solution: develop technology that works very quickly and does not increase refuel time.

- The ability to implement technology varies because of decentralized station ownership.

- Potential solution: engage the National Association of Convenience Store Owners and Petroleum Equipment Institute for outreach initiative on the availability, benefits, and costs of such systems.

The Federal Trade Commission has stated that there is no evidence of static energy sparks in conjunction with mobile phone use at a station (FTC 2016). Despite this, it is common practice to post a label on the dispenser warning that the use of mobile phones is not permitted (Figure 8). In some states, this type of stipulation may be a requirement. The rule originated from the mistaken belief that the use of a phone could create static and result in an explosion or fire.

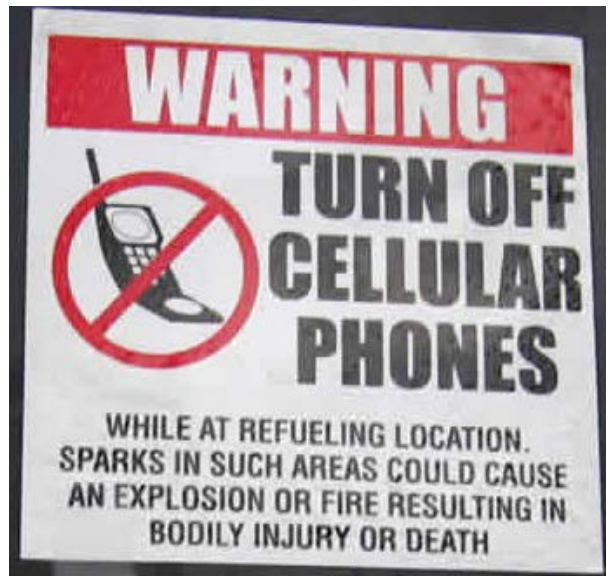

Figure 8. Phone warning label

\subsubsection{Dispenser Manufacturers}

Some existing truck stop payment systems deploy RFID technology in nozzles in order to automate payment for fleets. This is a potential issue for deployment on a national scale because it is not uncommon for consumers to accidentally drive away with them. The hanging hardware (nozzle, swivel, and hose) are designed to release from the dispenser if a vehicle pulls away with the nozzle still in the vehicle. Including technology in the nozzle makes the product more 
expensive and increases the financial loss in the event that a consumer drives away with it. Additionally, California and some other states require vapor recovery, and adding RFID to vapor recovery equipment would be difficult. The difficulty stems from the fact that the fit between the dispenser nozzle and the fill port is critical to correct operation of vapor recovery, and that adding a feature such as a ring-shaped RFID tag to the fill port while retaining correct operation of vapor recovery systems already in place would be challenging.

Growth in mobile payments and the need for upgraded systems and electronics indicates that the most likely equipment for a connected vehicle is the dispenser, as it is stationary and has an average lifespan of 15 years. Retail station dispensers are dominated by two manufacturers: Gilbarco Veeder-Root and Wayne Fueling Systems. Both organizations were interviewed as a part of this study for their input on methods to reduce or prevent misfueling.

Wayne Fueling Systems is evaluating multiple technologies for connected vehicle communication and has reviewed misfueling mitigation efforts. They state that the best solution to prevent misfueling is the connected vehicle approach, where the vehicle and dispenser communicate without consumer input. Currently, Bluetooth is attractive because of low costs, acceptable security protocols, and ease of development in both new and existing dispensers. Wayne stated the need for increased interaction between refueling equipment and vehicle manufacturers to streamline and standardize the process. This technology for connected vehicles puts the emphasis on the vehicle and dispenser, removing the need for consumer input. Other potential misfueling prevention technologies include high definition video in which a camera captures a vehicle as it parks at a dispenser to determine its compatibility with different fuel options. Wayne has also considered a mobile app with a customer vehicle database to prevent misfueling. Although Wayne has supplied RFID for many years, the challenge would be the high equipment costs and the need to develop a communication standard.

Gilbarco Veeder-Root has reviewed technology for the connected car as well. They consider the key issue to be the standardization of technology for vehicles to communicate with the dispenser. The Gasboy product line of fleet dispensers (owned by Gilbarco Veeder-Root) uses RFID technology for enabling refueling in payments with communication between the nozzle and a passive reader on the vehicle.

\subsection{Automotive Manufacturers}

Representatives from Ford Motor Company, General Motors, and Fiat-Chrysler Automobiles, North America were asked to provide input on misfueling mitigation within the context of the programmatic needs of the co-optimization program. Initial contacts with Ford, GM, and Chrysler were by email, followed by individual discussions by telephone. These companies chose to provide their input collectively, rather than individually.

The automotive manufacturers agreed that the misfueling mitigation study under the Co-Optima project is a worthwhile effort. They pointed out that some modern filler neck designs do resolve the misfueling issues between gasoline and diesel fuel, but that not all manufacturers have adopted such designs. In terms of new fuels, they noted that some potential fuel directions such as requiring premium-grade E10 gasoline might present less of a misfueling challenge. Mid-level (10\%-20\% by volume) ethanol blends are currently seen by the OEMs as the most viable approach to a future high-octane fuel, and the transition to a higher octane fuel may be 
sufficiently rapid that most legacy vehicles will not be compatible with the needed ethanol blend levels.

Additionally, the automotive manufacturers stated that solutions to the misfueling issue may depend on two types of cross-compatibility: new fuel into legacy vehicles and legacy fuel into new vehicles. They determined that at least one of these misfueling types would be likely (in the absence of an effective anti-misfueling measure) if the fuels differ in price or availability. With this issue in mind, misfueling mitigation should be considered throughout the industry rather than at specific manufacturers or fuel suppliers. Implementation details could vary by manufacturer but given a consistent approach at the fuel pump. The manufacturers agree that utilizing added personnel at the fueling point (either refueling attendants or cashiers to determine what fuel a vehicle should receive) to prevent misfueling is overly burdensome.

In terms of specific technological paths, the vehicle manufacturers indicated that vehicle side approaches should be installed in the vehicle, not done through an app or card or other item held by the driver. Bluetooth low energy (BLE) is a mature wireless communication standard that is well-known in the personal electronics industry. BLE solutions such as those being pursued by Toyota and Volkswagen are preferable to RFID options, as these contain privacy concerns and are not prepared for vehicle implementation. BLE is being used in vehicles and offers better security. Any approach should be simple and fail-safe, not reliant on Internet and smartphone access or outdated technology. Two-way communication between vehicle and pump seems complex and possibly prone to issues, but the manufacturers agreed that some fuel fill metrics obtainable via this path might be of interest to consumers and/or companies. This information might be useful in demonstrating fleet fuel usage for alternative fuel credits, for example. The manufacturers pointed out that recent hydrogen refueling efforts resulted in an IRDA wireless communication standard (SAE J2799) that could be useful in developing standards for liquid refueling.

\subsection{Ethanol Industry}

Initial contacts were made with both the Renewable Fuels Association (RFA) and Growth Energy by email, with subsequent teleconferences with both organizations and attendees they invited to participate on behalf of their industry.

The ethanol industry representatives had concerns with the Gilson Environmental report. They felt that the ratings of the potential misfueling mitigation strategies were arbitrary in some cases. However, they were not aware of any other similar source that should be considered in this discussion. Although they agreed that misfueling is a significant problem, they suggested that performing a study to identify the scope and scale of misfueling would be a worthy effort in addition to accelerating adoption of misfueling mitigation technologies. They pointed out that E15 market penetration might present an opportunity to do so. This suggestion was based on estimates that E15 sales volumes and fueling station availability will grow considerably during 2016 and 2017. The ethanol industry also considered the need to address other infrastructure issues, such as tankage at terminals, as a part of the Co-Optima effort.

In addition, the ethanol industry representatives noted that some filler neck designs do now resolve diesel fuel misfueling, but that not all manufacturers have adopted these designs. Also, legacy vehicles still have filler necks that don't prevent misfueling. They agreed that the best 
way to prevent misfueling is to take the driver and the attendant out of the equation to avoid human error.

In terms of misfueling mitigation strategies, the ethanol industry asserted that any new effort should focus not only on a holistic strategy that encompasses existing misfueling issues in the marketplace, but also on issues that may arise from the introduction of a new fuel. They agreed that vehicle-to-dispenser communication needs to have a technical standard to facilitate broad adoption. Within this context, the ethanol industry strongly recommended that the communication should be direct from the vehicle to the pump, not through other devices such as a cellular phone. This recommendation focuses on security, because reducing the number of devices involved in a transaction reduces the opportunity for security breaches to occur. Google and other non-traditional participants were mentioned as stakeholders who may also have valuable contributions to offer as they work with OEMs to develop technologies that connect vehicles with retail stations. The cost of these solutions was discussed as a potential issue, because the conversion to EMV credit card technology will make retailers hesitant to engage in another dispenser upgrade in the near future without some monetary support and clear business cases supporting investment in this technology.

\subsection{Misfueling Barriers and Potential Solutions}

Table 2 presents challenges and potential solutions identified in concert with stakeholder outreach conducted for the development of this report. These challenges and solutions focus on electronic means for preventing misfueling, rather than personnel- or label-based approaches.

Table 2. Misfueling Mitigation Barriers and Potential Solutions

Barrier

Competing or proprietary digital technologies

Consumers drive away with nozzle and vapor recovery (used in CA and other states), which makes the technology difficult.

Retailer reluctance after replacing or upgrading dispensers (average 15 year lifespan) to accommodate chip and pin credit cards

Availability of refueling equipment manufacturer to develop dispenser and misfueling mitigation hardware to support a new fuel is limited until after the 2017 adoption of chip and PIN credit card equipment.

RFID-based approaches do not offer robust information security.
Potential Solution

Create a standard for dispenser and vehicle manufacturers to facilitate a marketplace solution.

Technology at station should be in dispenser, not in the hanging hardware.

There will need to be a strong business case or a regulatory driver for a new fuel and misfueling mitigation technology deployment; capital will need to be identified to accelerate adoption.

Launch misfueling mitigation efforts by working on standards development; this pathway presents an opportunity for standardization to lead development and deployment of technologies in the marketplace and facilitate broad adoption.

Bluetooth low energy (BLE) is being deployed in vehicles now and provides information security as a part of existing standards. Adopt BLE or other more advanced communication standard for misfueling prevention technologies. 


\section{Codes and Standards Outreach}

Outreach was conducted to determine the appropriate contacts and method in which a standards committee and recommendation may be developed. SAE International is one of the leading developers of consensus-based standards for the automotive industry. SAE Standards committees have been contacted to determine the first steps in formalizing a committee (summarized below). Queries have been submitted to the appropriate committee chairs to determine the next steps. The following list summarizes the steps required for developing a misfueling mitigation standards committee (taken from SAE).

I. Identifying a Need: A new technical report begins when producers, purchasers, or anyone in industry identifies a need. In the case of the Co-Optima project, the need is to avoid misfueling legacy vehicles with potentially incompatible fuel(s), as well as protecting cars designed for a new fuel from being fueled with a legacy fuel. A proposal to create a new technical report requires concurrence from the respective committee. All projects must be in compliance with SAE Intellectual Property Policy.

II. Creating a Technical Committee: The Technical Committee is responsible for the preparation, development, and maintenance of all relevant technical reports within their scope. The technical committee shall consist of technical experts from government, industry, regulatory agencies, and academia relative to the Co-Optima project.

III. Requirements for Membership: Members contribute to the work of the Technical Committee, vote on all technical report ballots, and maintain active participants on the respective Technical Committee. Technical Committee members must be knowledgeable in the field(s) outlined by the Committee's scope.

IV. Responsibilities of the Technical Report Sponsor: The sponsor will serve as the focal point within the committee for activities associated with the development of a technical report. This includes preparation of all drafts and resolution of all comments received during the ballot process.

There are two types of technical reports.

1. SAE Recommended Practices: These are documentations of practices, procedures, and technology intended as guides to standard engineering practice. Their content may be of a more general nature, or they may present data that have not yet gained broad acceptance.

2. SAE Information Reports: These are compilations of engineering reference data or educational material useful to the technical community.

For this work, researchers should use the SAE-recommended practice technical report approach. 


\section{Steps in the Technical Report Approval Process:}

1. The document sponsor submits a draft to SAE for balloting in accordance with the official SAE consensus ballot process.

2. Committee members vote and provide comments on the draft.

3. Sponsor attempts to resolve all comments.

4. The technical report is balloted to the governing body of the initiating committee for a process level review.

5. Once approved by the governing body, SAE publishes the technical reports. 


\section{Conclusion and Recommendations}

As of this writing, misfueling mitigation in the marketplace is dominated by measures focusing on nozzle diameter differentiation, signage, and color of the nozzle handle. Electronic means of reducing or eliminating misfueling in the highway trucking sector are growing, with significant deployment at heavy-truck facilities. However, these technologies have not yet made progress in the light-duty fuel retailing marketplace. Connected-vehicle strategies for misfueling mitigation are on the horizon, but at this point, there is no technical standard in place to help guide and accelerate marketplace adoption of these technologies. Introducing new fuels that may not be fully backwards compatible to the marketplace will require misfueling mitigation strategies to protect legacy vehicles and equipment. Similarly, even if a new fuel is compatible with the legacy fleet, misfueling mitigation will be needed to prevent new vehicles designed to use a new fuel exclusively from being misfueled with a legacy fuel.

A number of stakeholder organizations have provided input for the misfueling mitigation project within the DOE Co-Optima program. These groups agree that the effort should support and enable accelerating existing technology development programs. Such supportive efforts include, for example, facilitating the development of technical standards for connected vehicle refueling approaches. Many stakeholders have also signaled their interest in participating in standard development activities.

Thus, this report recommends that the Co-Optima program should move toward assembling and launching standardization committees within relevant bodies. For example, the program could form a committee like SAE International with the objective of bringing stakeholders together to support misfueling mitigation efforts. The committee should formulate technologically achievable, practical, and effective frameworks to support these efforts for future vehicles and fuel dispensers in the marketplace. Standards bodies should be inclusive of all stakeholders in this technical area, and should encourage the participation of organizations that, although not traditionally part of the fuel and vehicle marketplace, now offer valuable viewpoints in this area. 


\section{References}

E15 Retailer Handbook. (2012). Renewable Fuels Association.

EPA. (2007, July 9). Letter to Diesel Fuel Retailers and Distributors.

EPA Mailout VPCD-97-01. (1997, January 24).

Federal Register. (2010, November 04). 75(213).

Federal Register. (2011, January 26). 76(17).

Federal Register. (2014, April 28). 79(81).

Federal Register. (2016, January 14). 81(9).

FTC. (n.d.). Federal Trade Commission. Retrieved June 3, 2016, from https://transition.fcc.gov/cgb/consumerfacts/wirelessgas.pdf

Fuel Economy.Gov. (n.d.). Retrieved May 18, 2016, from http://www.fueleconomy.gov/feg/powerSearch.jsp

Fuel Economy.Gov. (n.d.). Retrieved May 18, 2016, from http://www.fueleconomy.gov/feg/flextech.shtml

Gasboy. (2009). Gasboy PLUS series Brochure.

Gilson, E. (2010). Evaluation of Measures to Mitigate Misfueling of Mid- to High-Ethanol Blend Fuels at Fuel Dispensing Facilities. Gilson Environmental, LLC.

Hamstra, M. (2014, August 27). Mapco launches in-app payment with PayPal. Mobile Commerce Daily.

Heywood, J. B. (1988). Internal Combustion Engine Fundamentals. New York: McGraw-Hill, Inc.

Hirshfeld, D. K. (2014). Refining Economics of U.S. Gasoline: Octane Ratings and Ethanol Content. Environ. Sci. Technol., 48, 11064-11071.

Johnson, G. (2011, October 4). Some Truckers Hold Back on RFID, Cardless Fueling. Transport Topics.

NACS. (2015). 2015 NACS Retail Fuels Report.

Samuely, A. (2015, October 7). Chevron pumps in mobile payments to streamline filling up. Mobile Commerce Daily.

SAP. (n.d.). Retrieved June 1, 2016, from http://news.sap.com/sap-toyota-itc-verifone-connected-cars/

SAP. (n.d.). Retrieved June 1, 2016, from https://www.linkedin.com/pulse/shell-volkswagen-sapsimplifying-parking-refueling-hana-gerard-duong?articleId=8847680968841512218

Sluder, C. W. (2014). Determination of the R Factor for Fuel Economy Calculations Using EthanolBlended Fuels over Two Test Cycles. SAE Int. J. Fuels Lubr., 7(2).

Smartpay. (n.d.). Retrieved June 6, 2016, from https://www.cumberlandfarms.com/smartpay

Speedpass. (n.d.). Retrieved June 6, 2016, from https://www.speedpass.com 


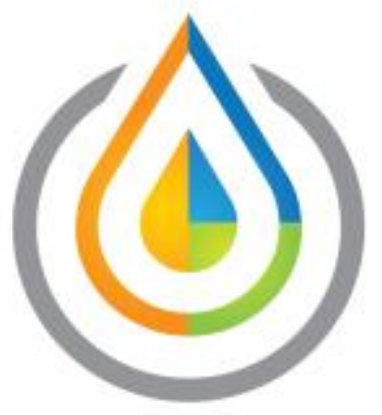
Us.openangent of

Energy Efficiency \& Renewable Energy 